\title{
Retrievals of thick cloud optical depth from the Geoscience Laser Altimeter System (GLAS) by calibration of solar background signal
}

Article

Published Version

Yang, Y., Marshak, A., Chiu, J. C., Wiscombe, W. J., Palm, S. P., Davis, A. B., Spangenberg, D. A., Nguyen, L., Spinhirne, J. D. and Minnis, P. (2008) Retrievals of thick cloud optical depth from the Geoscience Laser Altimeter System (GLAS) by calibration of solar background signal. Journal of the Atmospheric Sciences, 65 (11). pp. 3513-3526. ISSN 1520 0469 doi: https://doi.org/10.1175/2008JAS2744.1 Available at https://centaur.reading.ac.uk/16765/

It is advisable to refer to the publisher's version if you intend to cite from the work. See Guidance on citing.

To link to this article DOI: http://dx.doi.org/10.1175/2008JAS2744.1

Publisher: American Meteorological Society

All outputs in CentAUR are protected by Intellectual Property Rights law, including copyright law. Copyright and IPR is retained by the creators or other copyright holders. Terms and conditions for use of this material are defined in the End User Agreement. 


\section{www.reading.ac.uk/centaur}

\section{CentAUR}

Central Archive at the University of Reading

Reading's research outputs online 


\title{
Retrievals of Thick Cloud Optical Depth from the Geoscience Laser Altimeter System (GLAS) by Calibration of Solar Background Signal
}

\author{
Yuekui Yang, ${ }^{*}$ Alexander Marshak ${ }^{+}$J. Christine Chiu, ${ }^{\#}$ Warren J. Wiscombe, ${ }^{+}$ \\ Stephen P. Palm, ${ }^{@}$ Anthony B. Davis, $\stackrel{\gtrless}{ }$ Douglas A. SPAngenberg, ${ }^{@}$ Louis NGuyen, $* *$ \\ JAMES D. SPINHIRne, ${ }^{+}$AND PATrick Minnis** \\ * Goddard Earth Sciences and Technology Center, University of Maryland, Baltimore County, Baltimore, Maryland \\ + Goddard Space Flight Center, Greenbelt, Maryland \\ \# Joint Center for Earth Systems Technology, University of Maryland, Baltimore County, Baltimore, Maryland \\ @ Science Systems and Applications, Inc., Lanham, Maryland \\ \& Los Alamos National Laboratory, Los Alamos, New Mexico \\ **NASA Langley Research Center, Hampton, Virginia
}

(Manuscript received 23 January 2008, in final form 27 March 2008)

\begin{abstract}
Laser beams emitted from the Geoscience Laser Altimeter System (GLAS), as well as other spaceborne laser instruments, can only penetrate clouds to a limit of a few optical depths. As a result, only optical depths of thinner clouds ( $<$ about 3 for GLAS) are retrieved from the reflected lidar signal. This paper presents a comprehensive study of possible retrievals of optical depth of thick clouds using solar background light and treating GLAS as a solar radiometer. To do so one must first calibrate the reflected solar radiation received by the photon-counting detectors of the GLAS 532-nm channel, the primary channel for atmospheric products. Solar background radiation is regarded as a noise to be subtracted in the retrieval process of the lidar products. However, once calibrated, it becomes a signal that can be used in studying the properties of optically thick clouds. In this paper, three calibration methods are presented: (i) calibration with coincident airborne and GLAS observations, (ii) calibration with coincident Geostationary Operational Environmental Satellite (GOES) and GLAS observations of deep convective clouds, and (iii) calibration from first principles using optical depth of thin water clouds over ocean retrieved by GLAS active remote sensing. Results from the three methods agree well with each other. Cloud optical depth (COD) is retrieved from the calibrated solar background signal using a one-channel retrieval. Comparison with COD retrieved from GOES during GLAS overpasses shows that the average difference between the two retrievals is $24 \%$. As an example, the COD values retrieved from GLAS solar background are illustrated for a marine stratocumulus cloud field that is too thick to be penetrated by the GLAS laser. Based on this study, optical depths for thick clouds will be provided as a supplementary product to the existing operational GLAS cloud products in future GLAS data releases.
\end{abstract}

\section{Introduction}

The Geoscience Laser Altimeter System (GLAS) was launched on board the Ice, Cloud, and Land Elevation Satellite (ICESat) in January 2003 as part of the NASA Earth Observing System project (Spinhirne et al. 2005a). GLAS observes the earth at two wavelengths: the 532-nm channel, which uses photoncounting detectors, and the 1064-nm channel, which uses analog detection. More sensitive to atmospheric

Corresponding author address: Yuekui Yang, NASA Goddard Space Flight Center, Code 613.2, Greenbelt, MD 20771.

E-mail: yuekui@umbc.edu signals, the 532-nm channel is used as the primary channel for atmospheric products (Palm et al. 2002). Since its launch, GLAS has been providing data that contribute significantly to studying cloud and aerosol properties (e.g., Hart et al. 2005; Hlavka et al. 2005; Spinhirne et al. 2005b). However, the retrieved optical depths are limited to the relatively thin clouds that can be penetrated by the laser beam (< about 3 ).

Prior to the lidar retrieval process, the reflected solar energy has to be subtracted as noise from the signals received by the photon detectors. However, Platt et al. (1998, 2006) suggested that, if calibrated, the solar background can be viewed as a signal and used to retrieve cloud optical depths of dense clouds, thus com- 
pleting the cloud probing capability of active remote sensing with lidar. The reflected solar energy is recorded by GLAS in units of photon counts. Calibration is needed to convert photon counts into radiances. One path to calibration is from the instrumental parameters that are measured in the laboratory. This method suffers from the uncertainties stemming from degradation or change of the instrument during its deployment. Valencia et al. (2004) proposed a method using collocated NASA Aerosol Robotic Network (AERONET) sun photometers in calibrating the solar background of ground-based micropulse lidars (MPLs). Applying this method, Chiu et al. (2007) demonstrated encouraging results in retrieving cloud optical depths for thick clouds. Their validations against other instruments show that retrieved cloud optical depths agree within $10 \%-15 \%$ for overcast stratus and broken clouds.

In this paper, we present a comprehensive study of three possible ways of conducting on-orbit calibration of the reflected solar radiation received by the photoncounting detectors of the GLAS 532-nm channel. Section 2 gives basic information on GLAS solar background signals. The three calibration methods are introduced in section 3. Section 4 demonstrates the validation of the calibration by comparing Geostationary Operational Environmental Satellite (GOES) and GLAS retrievals of cloud optical depth (COD). A case study is presented in section 5 to illustrate how bonus information can be obtained from calibrated solar background signal in addition to the results of GLAS active remote sensing. Our conclusions are stated in section 6 .

\section{GLAS solar background signal}

To obtain the solar background signal, GLAS turns on the detectors for $256 \mu$ s (512 bins) at an altitude centered on approximately $100 \mathrm{~km}$. The background for each shot is computed from the average of the 512 bins (Palm et al. 2002). The signal obtained during this time consists only of background photons because at this height the molecular density of the atmosphere does not produce an appreciable Rayleigh signal and is devoid of particulates (detector dark current is also negligible).

The GLAS solar background data are archived in the products GLA02 and GLA07, uncalibrated and calibrated lidar signal profiles, with horizontal resolutions of $40 \mathrm{~Hz}(175 \mathrm{~m})$ and $5 \mathrm{~Hz}(1.4 \mathrm{~km})$ averaged over eight returns. These data are in units of raw photon counts and are stored before the detector dead-time correction is conducted. Dead time is a span of time immediately following the receipt of a photon during which the pho- ton counting detector is unable to record the arrival of additional photons (Campbell et al. 2002). The deadtime correction is performed by using a lookup table that contains a dead-time corrected value for each possible output from the photon counting channel (Palm et al. 2002). The dead-time corrected solar background photon counts are then used in the calibration process.

Proportional to the corrected photon counts $n$ (photon counts/bin) registered at the detectors, the radiance $L\left(\mathrm{~W} \mathrm{~m}^{-2} \mathrm{sr}^{-1} \mu \mathrm{m}^{-1}\right)$ of the reflected solar energy that reaches the GLAS instrument can be written as

$$
L=C n,
$$

where $C$ is the calibration coefficient [ $\mathrm{W} \mathrm{m} \mathrm{m}^{-2} \mathrm{sr}^{-1}$ $\mu \mathrm{m}^{-1} /$ (photon counts/bin)]. The calibration process is the practice of determining the calibration coefficient.

The GLAS data used in this study come from the first campaign with full on-orbit operation of the instrument (termed L2A) that began on 25 September and lasted until 19 November 2003 (Spinhirne et al. 2005a). During this campaign, over two thirds of the clouds observed by GLAS were not penetrated by the laser. Hence, calibrated solar background will provide important complementary information to the GLAS active remote sensing products. In addition, some GLAS active remote sensing data collected from later campaigns are of degraded quality due to technical problems with the lasers (Spinhirne et al. 2005b), but the photon detectors that receive solar background signals have remained stable: therefore, consistent COD retrievals can be expected from the properly calibrated solar radiation.

\section{Calibration methods}

To reduce uncertainties in the calibration, it is best to employ multiple independent methods. Three methods are used in this study: (i) calibration with collocated Moderate Resolution Imaging Spectroradiometer (MODIS)-Advanced Spaceborne Thermal Emission and Reflection Radiometer (ASTER) Airborne Simulator (MASTER) and GLAS observations, (ii) calibration with collocated observations of deep-convection clouds by GOES and GLAS observations, and (iii) calibration from first principles using optical depth of thin water clouds over ocean retrieved by GLAS active remote sensing.

\section{a. Calibration with collocated GLAS and airborne observations}

The airborne observation data employed in this study are from the GLAS validation experiment executed 
with the high-altitude NASA ER-2 aircraft from NASA Dryden Flight Research Center in Edwards, California, in October 2003 (Hlavka et al. 2005). The flight altitude is around $20 \mathrm{~km}$. Four instruments participated in the campaign: the MODIS-ASTER airborne simulator, the Cloud Physics Lidar (CPL), the Video Imaging System (VIS), and the MODIS Airborne Simulator (MAS). However, MAS was on the ER-2 for only three of the seven GLAS missions and none of them were during daytime. So, radiance observations from MASTER, which was on board the ER-2 for all seven missions, are used in this study.

MASTER was developed to support scientific studies by the ASTER and MODIS projects (Hook et al. 2001). In sunlit regions, the radiance observed by the ASTER 538-nm channel is close enough to the 532-nm channel of GLAS to be directly used in the calibration of the GLAS solar background. However, most of the October 2003 campaign flights were conducted at night. Among the seven flight missions, only the one that took place in the early morning of 24 October had sufficient sunlight along the track suitable for calibrating GLAS solar background radiances. Figure 1 gives the radiance image of the ASTER 538-nm channel observation (Fig. 1a) and the corresponding GLAS 532-nm channel attenuated backscatter image (Fig. 1b) for the track at the time of the GLAS overpass. A special feature of the GLAS satellite is the ability to accurately point the lidar to within $50 \mathrm{~m}$ of ground locations. Thus, comparison of the satellite and aircraft data is possible.

The size of the MASTER image (Fig. 1a) is $289 \times 36$ $\mathrm{km}^{2}$ with a pixel resolution of $50 \mathrm{~m}$. The horizontal resolution of the GLAS image (Fig. 1b) is $175 \mathrm{~m}$. For calibration purposes, observations from both instruments need to be collocated both in space and in time. Collocation in space is done with the nearest neighbor technique and the accuracy is within $50 \mathrm{~m}$ crosstrack. Then three MASTER pixels along the track are averaged to match the size of the GLAS sampling distance. Owing to the speed differences between the two platforms, most of the pixels collocated in space are not collocated in time. The image scan time for the MASTER was $22 \mathrm{~min} 24 \mathrm{~s}$, whereas for GLAS it was 42 s. To minimize the ensuing uncertainties, we limit the pixels used in this study to those within 5-min time differences between the two observations (marked by the double arrow lines in Figs. 1a and 1b). Figure 2 gives the flowchart of the calibration process.

Figure 3 shows the calibration result. The two pixel clusters in Fig. 3 represent the collocated clear and cloudy pixels. As is customary in instrument calibration (e.g., Nguyen et al. 2001), the regression line is forced through the origin. Physically, this is because, corre- sponding to zero photon counts, the solar background radiance must be zero as well. Equation (2) gives the regression:

$$
L=6.62 n \text {. }
$$

The calibration coefficient derived with this method is $C=6.62 \mathrm{~W} \mathrm{~m}^{-2} \mathrm{sr}^{-1} \mu \mathrm{m}^{-1} /($ photon counts/bin), and the one-sigma error of the slope is 0.06 .

When the radiances corresponding to the solar background photon counts of each selected point are calculated using Eq. (2) and then compared to the MASTER observations, the mean difference is $4.1 \%$, with a standard deviation of $3.3 \%$. A variety of sources may contribute to this calibration uncertainty, including the remaining space and time difference and the size difference between the pixels.

\section{b. Calibration with collocated deep-convection clouds observed from GLAS and GOES}

The second approach employs collocated GLAS and GOES visible-channel deep convection observations. Because of the single line nature of GLAS images, exact collocations in time are rare between the spatially collocated GOES and GLAS pixels. However, because of the horizontal homogeneity of deep convective systems and relatively weak fluctuation in radiances reflected from very thick clouds, we can assume that small differences in time and space between the selected GLAS and GOES pixels would not cause significant bias in the calibration results. After collocated deep convective observations are selected, the solar energy differences between the GOES visible channel $(0.65$ $\mu \mathrm{m})$ and the GLAS green channel $(0.532 \mu \mathrm{m})$, as well as the view angle differences between the observations from the two instruments, must be taken into account in the calibration process.

The following criteria for selecting deep convection points are employed: (i) GOES $10.7-\mu \mathrm{m}$ channel brightness temperature $<205 \mathrm{~K}$ and its $3 \times 3$ pixel standard deviation $<1 \mathrm{~K}$, (ii) the $3 \times 3$ pixel standard deviation of the GOES $0.65-\mu \mathrm{m}$ channel raw count $<3 \%$ of the central pixel raw count, (iii) GLAS reported cloud top height $>10 \mathrm{~km}$, and (iv) temperature at cloud top from GLAS products $<208 \mathrm{~K}$. In addition, to have sufficient sunlight, the solar elevation angles for the selected points had to be $>12^{\circ}$. Twenty-one collocated deep convection points are found with GOES-10 and GOES-12 data during the GLAS L2A campaign period. Table 1 lists these points; entries having longitudes $<-105^{\circ}$ are from GOES-10. As shown in the table, owing to the differences in the observation strategies of the two instruments, the selected pixels are collocated 


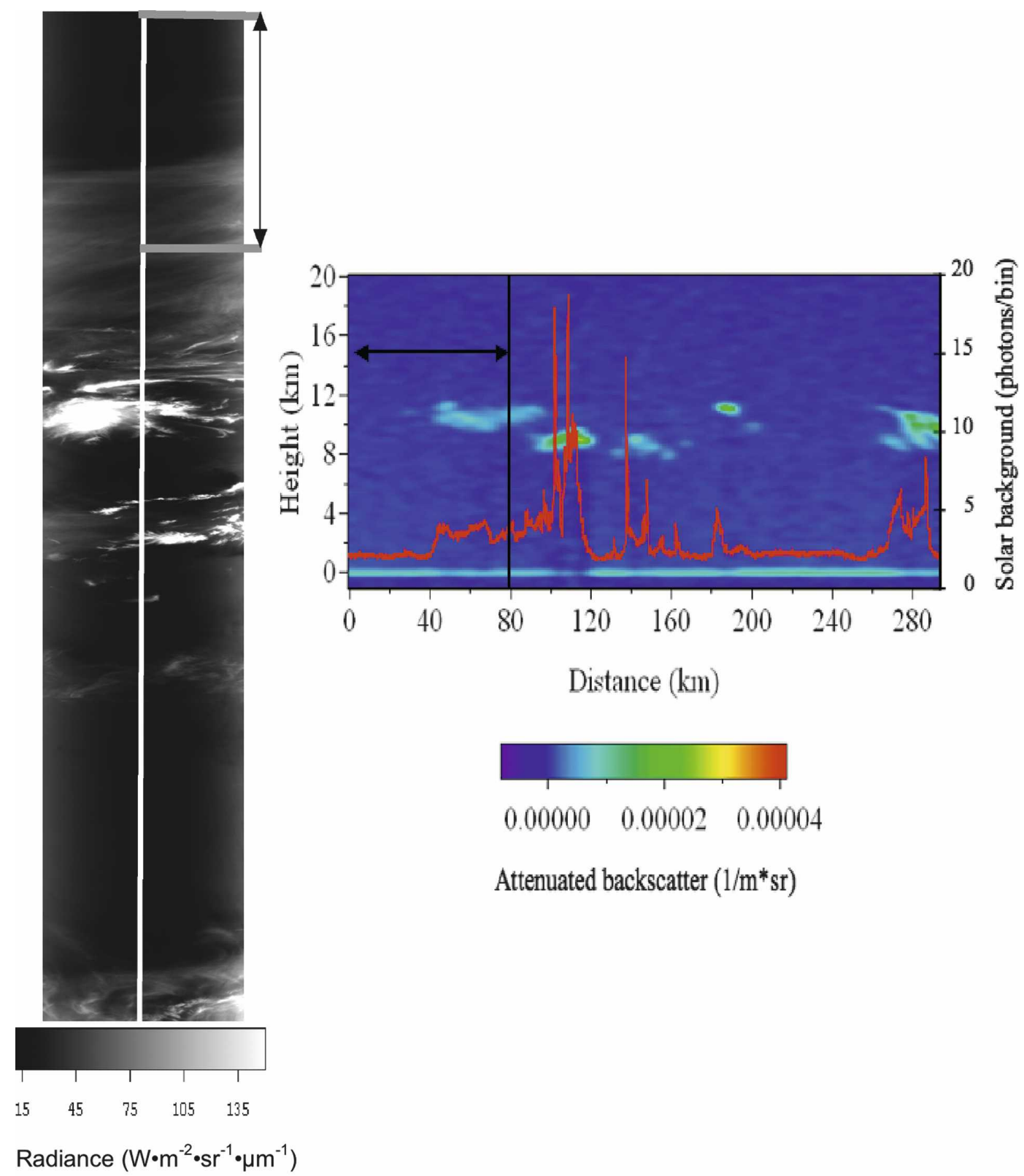

\section{(a)}

(b)

FIG. 1. (a) The MASTER 538-nm image from the 24 October 2003 flight off the west coast of California. The thick white line in the middle of the image represents the GLAS track. The double arrow line marks the region that has time differences less than five minutes between GLAS and MASTER observations. (b) The corresponding GLAS 532-nm attenuated backscatter image with the corresponding solar background photon counts. The double arrow line marked the same region as marked in (a).

in space, although differences exist in the observation time.

Figure 4 gives the flowchart of the calibration process with this method. Since the pixel sizes of GLAS (175 m) and GOES $(4 \mathrm{~km})$ are different, the GLAS solar background signal is averaged to match the GOES pixel resolution. The GOES-10 and 12 radiances are first calibrated to the corresponding Terra MODIS $0.63-\mu \mathrm{m}$ channel using the methods described by Minnis et al. (2002). They are then adjusted to a 532-nm wavelength from the original $630-\mathrm{nm}$ measurements with the following equation: 


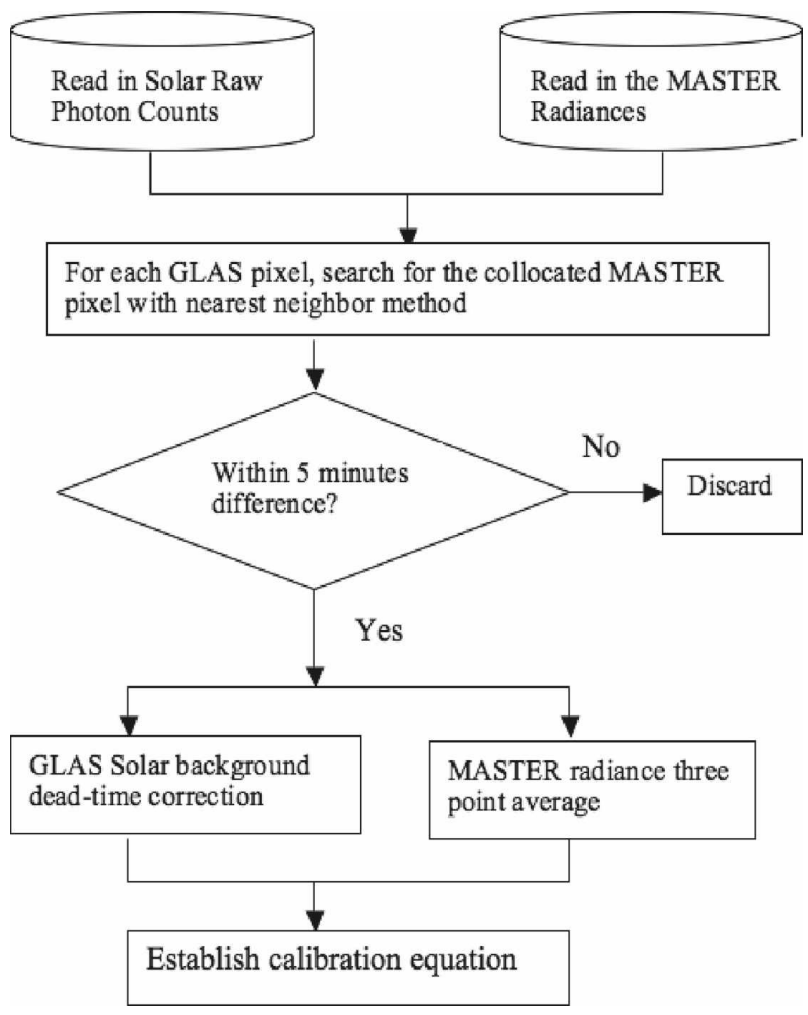

FIG. 2. Flowchart of calibrating GLAS solar background signal with the collocated MASTER observations.

$$
L_{532}=L_{650} \times \frac{M_{532}}{M_{630}},
$$

where $M_{532}=1869 \mathrm{~W} \mathrm{~m}^{-2} \mu \mathrm{m}^{-1}$ is the solar spectrum irradiance at $532 \mathrm{~nm}$ and $M_{630}=1641 \mathrm{~W} \mathrm{~m}^{-2} \mu \mathrm{m}^{-1}$ is the solar spectrum irradiance at $630 \mathrm{~nm}$ (American Society for Testing and Materials 2000).

As listed in Table 1, the view angles of the selected GOES observations are always away from nadir. These view angle differences are taken into account by using the angular distribution models (ADMs) developed by the Clouds and the Earth's Radiant Energy System (CERES) Inversion Working Group (Loeb et al. 2001) with the following equation:

$$
L_{0}\left(\theta_{0}\right)=L_{\theta}\left(\theta_{0}, \varphi_{0}\right) \times \frac{\operatorname{ADM}_{0}\left(\theta_{0}\right)}{\operatorname{ADM}_{\theta}\left(\theta_{0}, \varphi_{0}\right)},
$$

where $L_{0}\left(\theta_{0}\right)$ is the radiance at nadir for solar zenith angle $\theta_{0}, L_{\theta}\left(\theta_{0}, \varphi_{0}\right)$ is the radiance at view angle $\theta$ for solar zenith angle $\theta_{0}$ and solar azimuth angle $\varphi_{0}, \operatorname{ADM}_{0}\left(\theta_{0}\right)$ is the ADM value at nadir for solar zenith angle $\theta_{0}$, and $\operatorname{ADM}_{\theta}\left(\theta_{0}, \varphi_{0}\right)$ is the $\mathrm{ADM}$ value at view angle $\theta$ for solar zenith angle $\theta_{0}$ and solar azimuth angle $\varphi_{0}$.

Figure 5 shows the calibration results with this

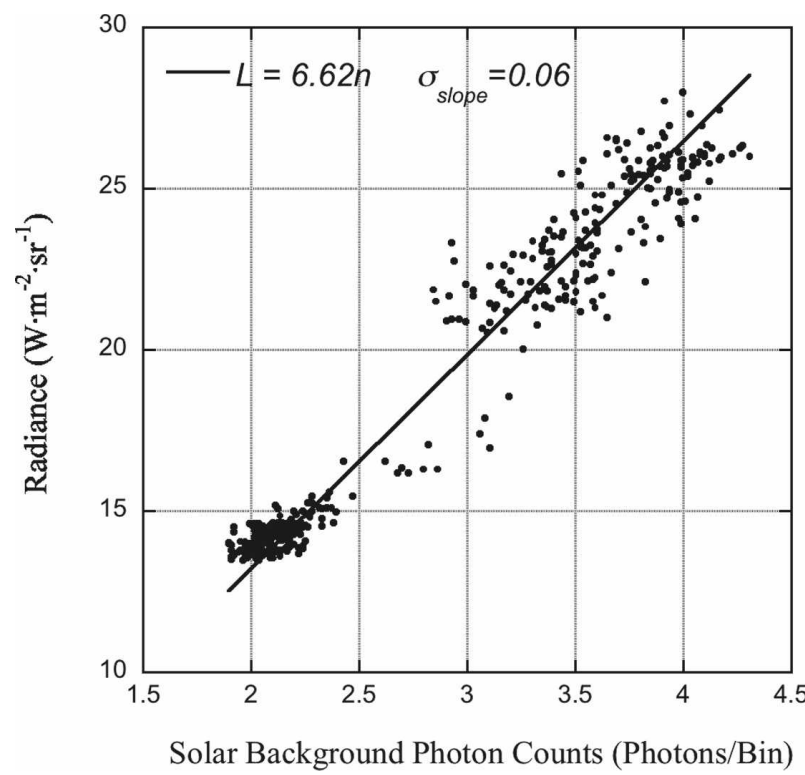

FIG. 3. Calibration of GLAS solar background signal with collocated MASTER observations. The calibration equation and the uncertainty in the slope are shown in the upper left corner of the figure. Total number of points is 450 .

method. As with the first method, the regression line is forced through the origin:

$$
L=6.36 n \text {. }
$$

The calibration coefficient derived with this method is $C=6.36 \mathrm{~W} \mathrm{~m}^{-2} \mathrm{sr}^{-1} \mu \mathrm{m}^{-1} /$ (photon counts/bin) and the one-sigma error of the slope is 1.63 .

A variety of factors can cause uncertainties to the calibration coefficient determined with this method. First, the adjustment process of the GOES radiance data may bring inaccuracy. For example, the CERES ADMs are derived with broadband observations. Even though the bandwidth of the GOES visible channel is fairly wide $(0.52-0.72 \mu \mathrm{m})$, remapping GOES off-nadir observations to nadir with CERES ADMs can still result in biases. Second, the collocation process can be another error source. For example, time differences exist in the collocated pixels. The largest difference (corresponding to the smallest, $<150 \mathrm{~W} \mathrm{~m}^{-2} \mathrm{sr}^{-1}$, radiance in Fig. 5) is for Point 17 in Table 1, which is for a 0.24-h (14.4 min) time difference. Even though the reflected solar energy for deep convective clouds is usually stable, the differences in observation time can still cause uncertainty to the calibration coefficient.

\section{c. Calibration from first principles}

The third approach takes advantage of the active remote sensing results from GLAS. It involves three 
TABLE 1. Collocated GOES and GLAS pixels during the L2A campaign in October-November 2003.

\begin{tabular}{|c|c|c|c|c|c|c|c|}
\hline \multirow[b]{2}{*}{ Point } & \multirow[b]{2}{*}{ Date } & \multirow[b]{2}{*}{ Latitude $\left({ }^{\circ}\right)$} & \multirow[b]{2}{*}{ Longitude $\left({ }^{\circ}\right)$} & \multicolumn{2}{|c|}{ GOES } & \multicolumn{2}{|c|}{ GLAS } \\
\hline & & & & Time (h UTC) & View angle $\left({ }^{\circ}\right)$ & Time (h UTC) & View angle $\left({ }^{\circ}\right)$ \\
\hline 1 & 5 Oct & 9.53 & -71.46 & 12.89 & 11.95 & 12.95 & Nadir \\
\hline 2 & $5 \mathrm{Oct}$ & 9.28 & -71.50 & 12.89 & 11.67 & 12.95 & Nadir \\
\hline 3 & 10 Oct & -4.06 & -63.76 & 12.44 & 14.60 & 12.21 & Nadir \\
\hline 4 & 11 Oct & -11.20 & -67.66 & 12.46 & 16.04 & 12.41 & Nadir \\
\hline 5 & 11 Oct & -11.70 & -67.73 & 12.46 & 16.47 & 12.41 & Nadir \\
\hline 6 & 11 Oct & -11.95 & -67.76 & 12.47 & 16.69 & 12.41 & Nadir \\
\hline 7 & 11 Oct & -12.20 & -67.80 & 12.47 & 16.92 & 12.41 & Nadir \\
\hline 8 & 11 Oct & 9.09 & -161.65 & 18.64 & 32.75 & 18.76 & Nadir \\
\hline 9 & 14 Oct & 6.80 & -73.96 & 12.9 & 8.20 & 12.82 & Nadir \\
\hline 10 & 18 Oct & 17.08 & -84.21 & 13.36 & 22.42 & 13.42 & Nadir \\
\hline 11 & 21 Oct & -11.20 & -72.70 & 12.46 & 13.58 & 12.43 & Nadir \\
\hline 12 & 21 Oct & 9.33 & -142.46 & 17.14 & 14.03 & 17.17 & Nadir \\
\hline 13 & 21 Oct & 9.08 & -142.50 & 17.14 & 13.83 & 17.17 & Nadir \\
\hline 14 & 21 Oct & 8.84 & -142.54 & 17.14 & 13.64 & 17.17 & Nadir \\
\hline 15 & 21 Oct & 7.84 & -142.68 & 17.15 & 12.89 & 17.17 & Nadir \\
\hline 16 & 21 Oct & 6.03 & -167.12 & 18.65 & 37.96 & 18.79 & Nadir \\
\hline 17 & 29 Oct & 12.84 & -92.79 & 13.38 & 25.56 & 13.62 & Nadir \\
\hline 18 & $4 \mathrm{Nov}$ & -9.21 & -40.79 & 9.95 & 40.97 & 9.87 & Nadir \\
\hline 19 & $4 \mathrm{Nov}$ & -9.46 & -40.83 & 9.96 & 41.00 & 9.87 & Nadir \\
\hline 20 & $4 \mathrm{Nov}$ & -9.71 & -40.86 & 9.96 & 41.03 & 9.87 & Nadir \\
\hline 21 & $7 \mathrm{Nov}$ & 9.10 & -71.25 & 11.93 & 11.57 & 11.88 & Nadir \\
\hline
\end{tabular}

steps: (i) determining the reflected solar radiances using radiative transfer calculations for GLAS-retrieved thin cloud optical depths as input, (ii) selecting points with the lowest solar background at each cloud optical depth, and (iii) deriving the calibration equation from the calculated radiances and the measured solar background photon counts. The thin cloud optical depth is a standard GLAS product (GLA11) that is retrieved from analysis of the lidar backscattered signal (Spinhirne et al. 2005b). By a thin cloud, we refer to a cloud

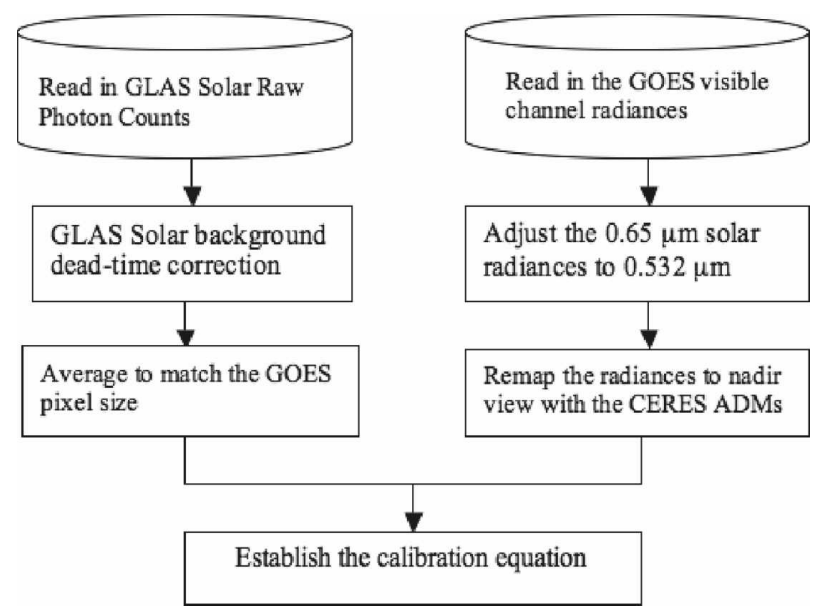

FIG. 4. Flowchart of calibrating GLAS solar background signal with the collocated GLAS and GOES deep convection observations. that does not completely attenuate the lidar signal (generally, with optical depth smaller than $\sim 3$ ).

Figure $6 \mathrm{a}$ plots the solar background photon counts versus the GLAS GLA11 cloud optical depths over ocean for the GLAS L2A campaign. Due to the uncertainties in the phase function of ice clouds, only singlelayer liquid clouds (with cloud top height $<3500 \mathrm{~m}$ )

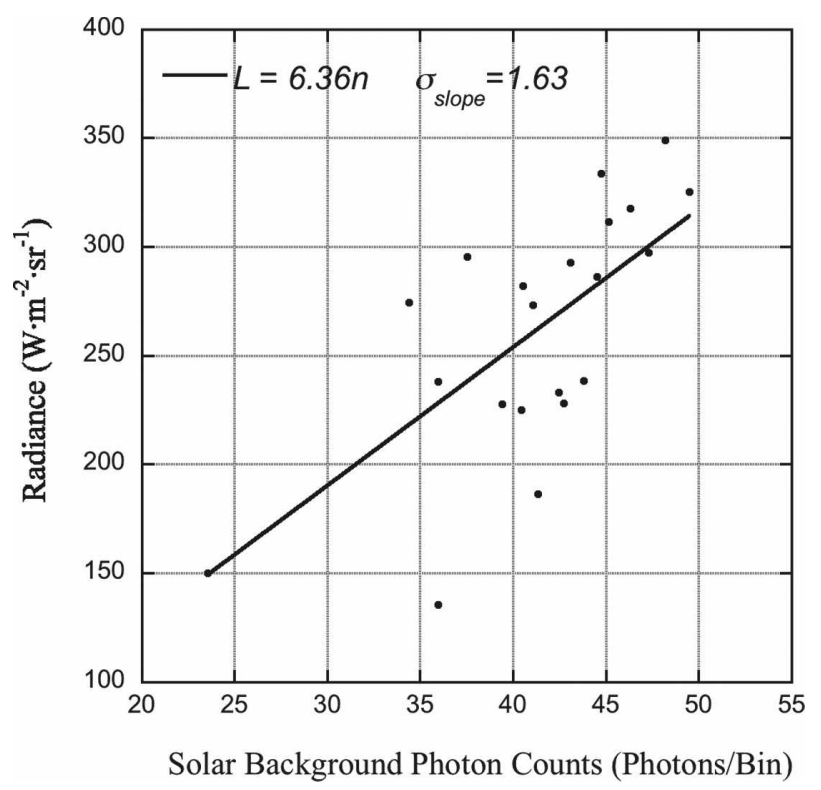

FIG. 5. Calibration of GLAS solar background signal with the collocated GOES deep-convection cloud observations. 

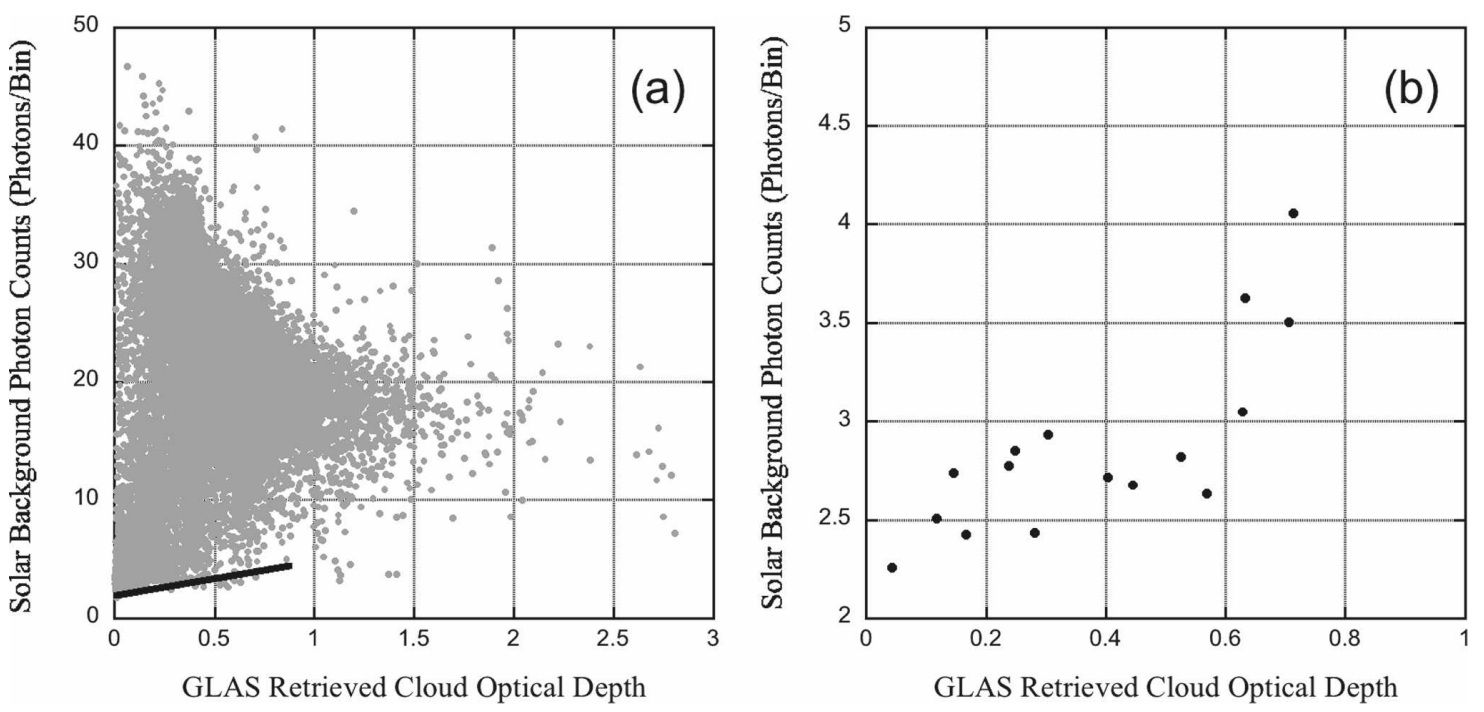

FIG. 6. (a) GLAS retrieved cloud optical depth vs solar background photon counts for water clouds. The thick black line (approximately) represents the lower boundary of the scattered points. (b) Selected points used in the calibration process.

have been selected. The plot contains around 18000 points that have solar zenith angles ranging from $60^{\circ}$ to $70^{\circ}$. As shown in the figure, there is a wide spread in the values of solar background photon counts that correspond to each retrieved cloud optical depth. A variety of reasons, such as surface reflectance variability, differences in aerosol loading, cloud microphysics, and uncertainties in the retrieval process, can result in different solar reflectance for clouds with the same optical depth. It would not be practical to determine the atsensor solar radiances for all the points. However, the lower boundary of the scattered points, which is marked as a thick line in Fig. 6a, represents the observations with the lowest solar background that corresponds to the lowest surface reflection and the least aerosol loading. It is feasible to calculate the reflected solar radiances corresponding to these observations using radiative transfer models. Figure $6 \mathrm{~b}$ shows GLAS retrieved cloud optical depths versus the solar background photon counts for these points, which are selected through the following procedure: (i) the observations are binned with an optical depth interval of 0.2 , (ii) points with optical depths smaller than 0.02 and larger than 0.8 are excluded to keep only the most reliable GLAS retrievals, and (iii) four points with the lowest solar background photon counts in each bin are selected. We limited the data to only warm water clouds to avoid additional uncertainties related to the scattering phase function.

To determine the at-sensor solar radiances corresponding to the selected points, radiative transfer calculations are conducted with the Discrete Ordinates
Radiative Transfer (DISORT) program for a multilayered plane-parallel medium model (Stamnes et al. 1988) for the cloud optical depth retrieved from GLAS active remote sensing. As the selected points represent observations with the lowest surface reflection and the least aerosol loading, the radiative transfer calculations are carried out under the following assumptions: (i) the wind speed according to the Cox and Munk (1954) model is assumed to be small $\left(5 \mathrm{~m} \mathrm{~s}^{-1}\right)$, (ii) the aerosol optical depth is assumed to be 0 (lowest aerosol loading), and (iii) the cloud effective radius $R_{\text {eff }}$ is assumed to be $10 \mu \mathrm{m}$. (The uncertainty caused by this assumption is studied and presented in Fig. 8.)

Figure 7 gives the flowchart of the calibration process with this method, and Fig. 8 shows the calibration results. If the regression is forced through the origin, then

$$
L=6.35 n
$$

Hence, the calibration coefficient derived with this method is $C=6.35 \mathrm{~W} \mathrm{~m}^{-2} \mathrm{sr}^{-1} \mu \mathrm{m}^{-1} /$ (photon counts/ bin) and the one-sigma error of the slope is 0.84 . As mentioned above, the radiances are calculated by assuming a cloud droplet size of $10 \mu \mathrm{m}$. The vertical error bars in Fig. 8 give the uncertainties caused by a typical range of droplet effective radius $\left(6 \mu \mathrm{m} \leq R_{\text {eff }} \leq 16\right.$ $\mu \mathrm{m})$. As seen in the figure, the uncertainties are small (with a maximum value of $4.3 \%$ ) and do not affect the calibration coefficient significantly. If we assume a cloud droplet size of 6 or $16 \mu \mathrm{m}$, the corresponding calibration coefficients would be 6.54 and $6.27 \mathrm{~W} \mathrm{~m}^{-2}$ $\mathrm{sr}^{-1} \mu \mathrm{m}^{-1} /($ photon counts/bin), respectively. 


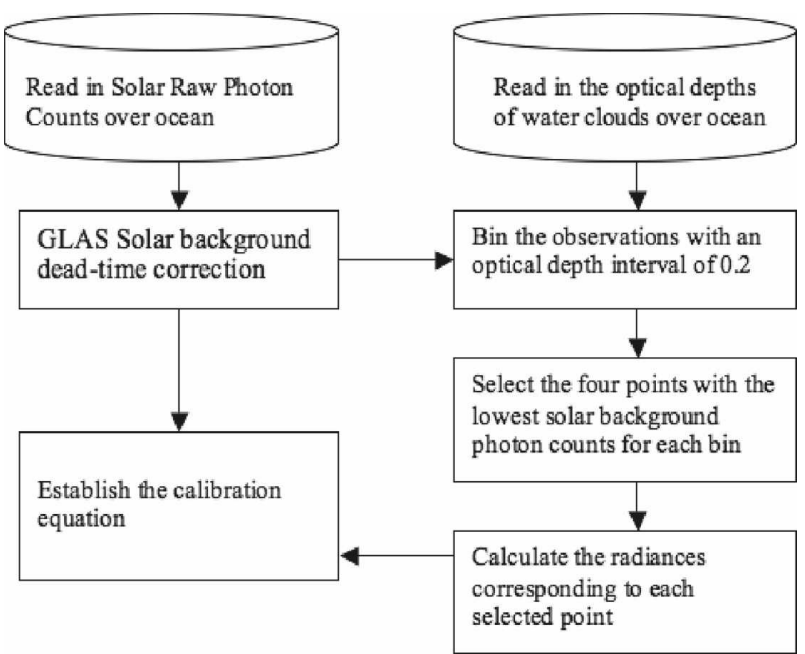

FIG. 7. Flowchart of calibrating GLAS solar background signal with the cloud optical depths retrieved from GLAS active remote sensing.

\section{d. Combination of the three methods}

The calibration coefficients $(6.62,6.36$, and 6.35$)$ derived from the three methods agree well with each other, with differences less than $4.2 \%$. To finalize the results, all points used in the three methods are consolidated together and plotted in Fig. 9.

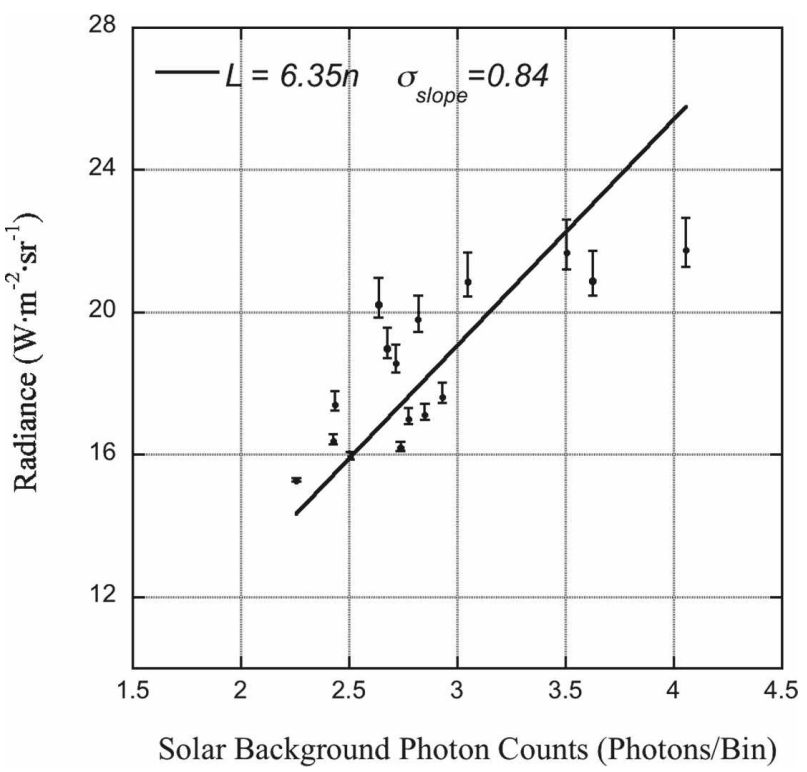

FIG. 8. Calibrating GLAS solar background signal with the thin cloud optical depths retrieved from GLAS active remote sensing (data product GLA11). The selected points correspond to the lowest values of solar background for each optical depth (see text for details). The calibration coefficient is derived by assuming a cloud droplet size with $R_{\text {eff }}=10 \mu \mathrm{m}$. The error bars give the uncertainties caused by the range of a possible $R_{\text {eff }}\left(6 \mu \mathrm{m} \leq R_{\text {eff }} \leq\right.$ $16 \mu \mathrm{m})$.

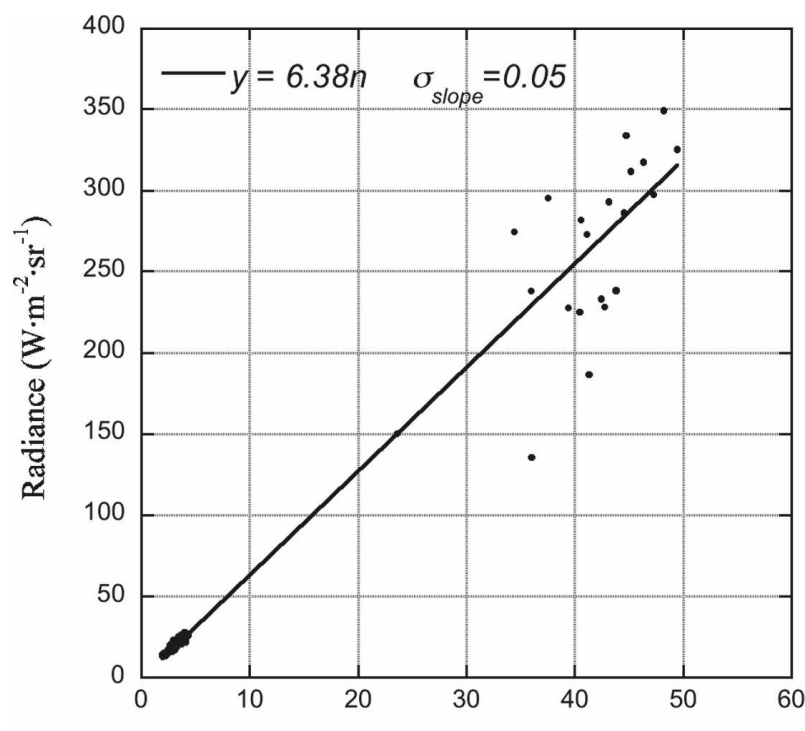

Solar Background Photon Counts (Photons/Bin)

FIG. 9. Calibration of the GLAS solar background signal with all of the data used by the three methods.

Equations (7) and (8) give the linear regression relations between the solar background $x$ and the reflected solar radiance $L$ with and without forcing the regression line through the origin:

$$
\begin{aligned}
& L=6.38 n, \\
& L=6.34 n+0.84 .
\end{aligned}
$$

Based on this, we determine the final calibration coefficient $C=6.38 \mathrm{~W} \mathrm{~m}^{-2} \mathrm{sr}^{-1} \mu \mathrm{m}^{-1} /$ (photon counts/bin). The one-sigma error of the least squares slope is 0.05 .

\section{Comparison of COD retrievals from GLAS solar background and from GOES}

\section{a. Data}

Once calibrated, the reflected solar background signal received by the GLAS photon counters can be employed in retrieving the optical depths of thick clouds. The retrieval process is straightforward. First, a lookup table that gives solar radiances as a function of solar zenith angle and cloud optical depth is computed from DISORT (Stamnes et al. 1988). The intervals for solar zenith angle and cloud optical depth are $2^{\circ}$ and 0.1, respectively. As the retrieval is based on the information from a single channel, we have to make an assumption about the value of the effective radius of the cloud droplets. In this study, we use $R_{\text {eff }}=10 \mu \mathrm{m}$ as a baseline value. As will be shown later, the possible bias caused by this assumption is usually within $10 \%$. As a 


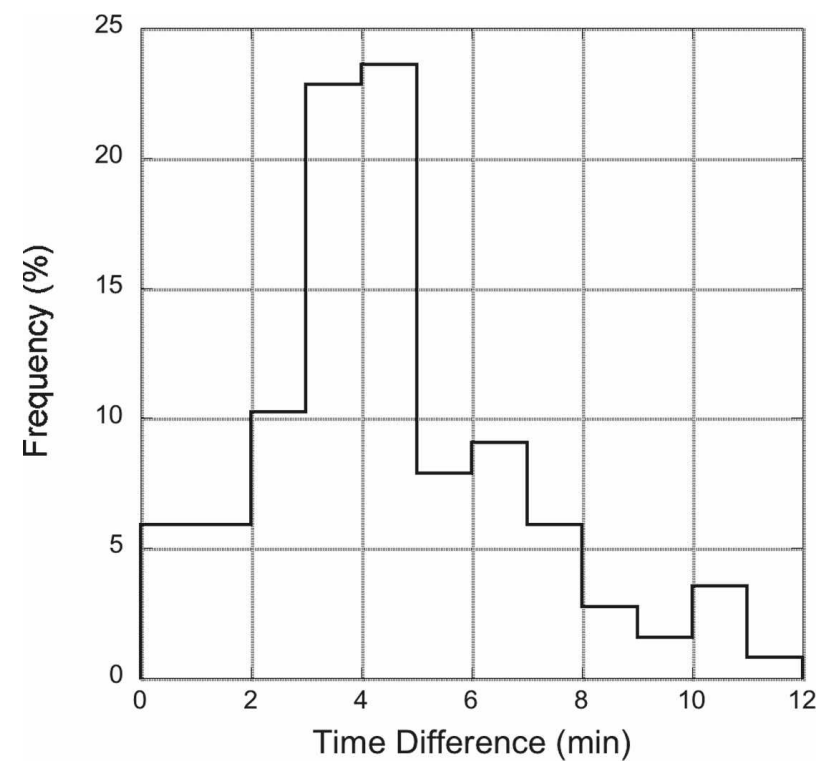

FIG. 10. Distribution of time differences between selected GLAS and GOES observations.

first-order approximation, we assume that the surface is not reflective. The solar zenith angle of the GLAS data used in this study ranges between $50^{\circ}$ and $80^{\circ}$. Within this range, the Cox-Munk model tells us that the ocean nadir reflectance is about $0.5 \%-2 \%$ depending on the wind speed; this is insignificant for comparison with the GOES retrievals, especially for optically thick clouds. Finally, the at-sensor solar radiance of GLAS solar background is calculated with Eq. (7).

To test the validity of the COD retrievals from GLAS solar background, we compare them with the independent retrievals from GOES. The collocated GLAS and GOES observations of deep convective clouds used in the calibration process (section $3 \mathrm{~b}$ ) are excluded from comparison. The cloud properties from the GOES data are determined with the "Visible IR Solar-IR Split Window Technique" (VISST) (Minnis et al. 1995, 1998), which categorizes clouds into water, ice, and supercooled liquid water phases. To simplify the comparison, we only use clouds with water or supercooled liquid water phases over ocean.

Given the large region covered by GOES, a significant amount of spatially collocated points between GLAS and GOES can be found. However, the time differences between the two observations could be large. For this study, we use only the spatially matched GLAS and GOES data points that occur within $15 \mathrm{~min}$ of each other. All together, 741 points were found that satisfy the aforementioned requirement. Figure 10 gives the distribution of time differences between the two observations for the selected points.
Another problem in comparing GOES and GLAS COD retrievals is the different spatial resolution. The GOES cloud optical depth is taken from an approximate $16 \times 16 \mathrm{~km}^{2}$ area centered on the GLAS point, whereas the GLAS footprint is $175 \mathrm{~m}$. Consequently, the GLAS solar background signal has to be averaged over 92 points to ensure maximal overlap between the two retrievals. Since the area used to obtain the mean GLAS data values $\left(175 \times 16100 \mathrm{~m}^{2}\right)$ has a different spatial size and shape compared to the GOES retrieval footprint, significant discrepancies are to be expected between the two retrievals for inhomogeneous cloud fields. This will be demonstrated in the next section.

\section{b. Results of comparison}

Figure 11 shows the results of comparing the cloud optical depths retrieved from the GLAS 532-nm solar background and from GOES. As seen from Fig. 11a, there is a wide scatter of points with a bias toward higher COD retrieved from GOES. As mentioned above, the main source of discrepancy here is the difference in spatial resolution of the two datasets; this is especially true for highly inhomogeneous clouds. To illustrate, we calculated the standard deviation of the 92 GLAS points corresponding to the GOES retrieval footprint. The standard deviation represents the amount of cloud horizontal inhomogeneity. The smaller the standard deviation is, the more likely that the observed clouds with the two instruments share the same properties and the closer the retrievals should be to each other. Indeed, if the standard deviation is limited to $25 \%$ of the corresponding mean value, a much better correlation with essentially no bias between the two retrievals is achieved (Fig. 11b). On average, the relative difference, which is the mean absolute difference between GLAS and GOES COD over the mean of GOES COD, is $24 \%$. And the relative root-meansquare difference, which is the rms of the difference between GLAS and GOES COD over the rms of GOES COD, is $28 \%$. These differences are comparable to the respective $32 \%$ and $25 \% \mathrm{rms}$ differences between MODIS and GOES optical depth retrievals using the VISST and those based on measurements taken at the surface (Dong et al. 2002, 2008).

Figure 11c illustrates examples of the radiance distributions for the two points highlighted in Fig. 11a, one with large standard deviation in GLAS data (labeled "L" in Fig. 11a), and the other with small standard deviation (labeled "S"). As seen from Fig. 11c, a small shift in space for the large standard deviation case would result in a large difference in radiance and hence a large difference in the retrieved COD, whereas the small standard deviation case does not have this prob- 

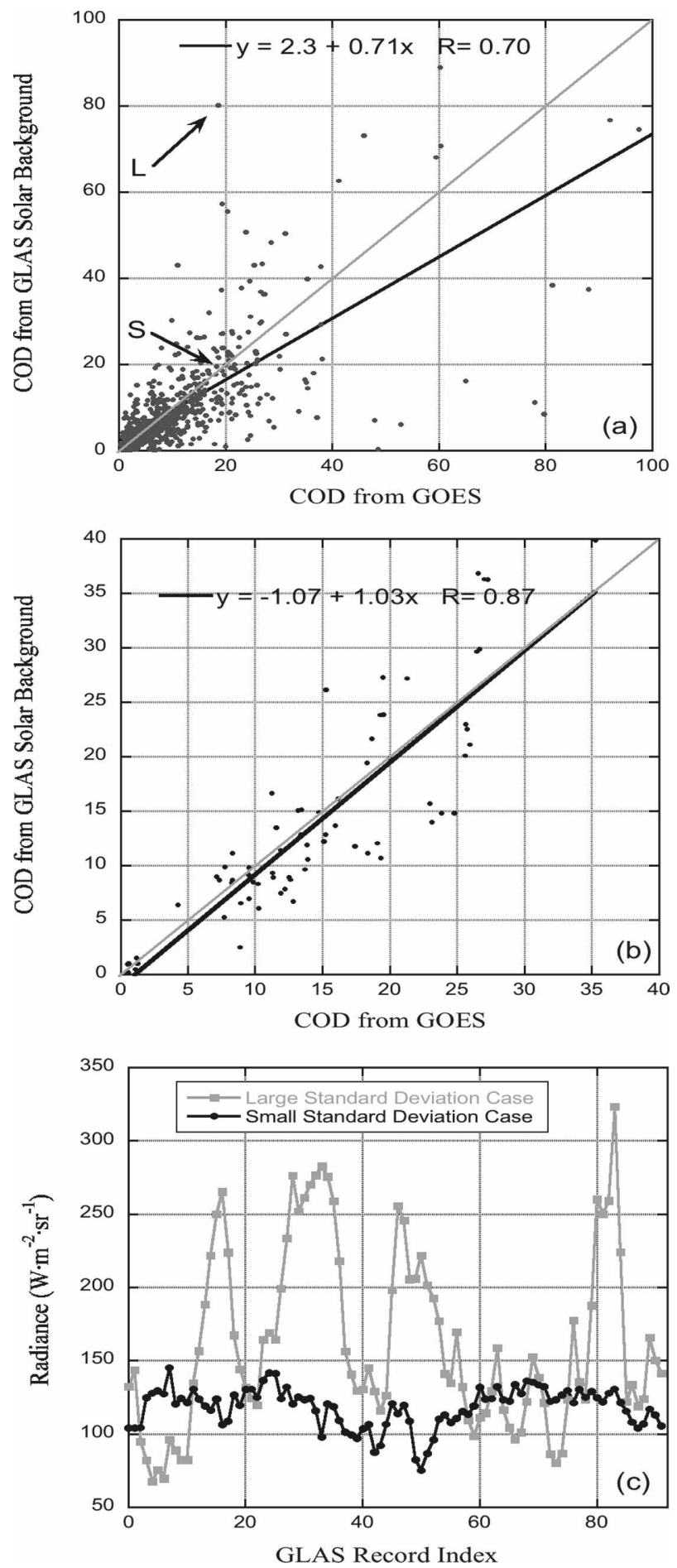

FIG. 11. Comparison of cloud optical depth (COD) retrievals from GLAS 532-nm solar background and from the GOES satellites. The GOES retrieval footprint is $16 \times 16 \mathrm{~km}^{2}$ and the GLAS retrieval is derived from the mean radiance of $92175-\mathrm{m}-$ resolution data values. (a) Results for all 741 available GOES points. Only retrievals with COD $<100$ are plotted, leaving 17 points outside the plot area. The two points marked in the figure represent cases with large $(L)$ and small $(S)$ std dev of the GLAS data. (b) Results for the selected 73 points that have a std dev lem and hence provides a good match between the GLAS and GOES retrievals.

Two additional factors of the GLAS COD retrieval process may affect the correlation between the retrievals from the two instruments. The first factor is that the one-channel retrievals from GLAS solar background assume a fixed cloud droplet effective radius (here 10 $\mu \mathrm{m})$. The uncertainty arising from this assumption is illustrated in Fig. 12a. The upper and lower bounds of the retrieved COD are determined by assuming an effective radius of 6 and $16 \mu \mathrm{m}$, respectively. Based on the retrieved GOES effective radii, the $6-16-\mu \mathrm{m}$ range covers $82 \%$ of the data. As shown in Fig. 12a, the rms retrieval errors resulting from the uncertainty in effective radius is $7 \%$.

The other factor that can cause errors in the GLAS retrievals is the uncertainty in the calibration coefficient of GLAS solar background. As discussed in section 3 , the difference among the calibration coefficients derived from the three individual methods is within $4.2 \%$. Here we assumed a $5 \%$ uncertainty in the calibration coefficient, which led to the error bars plotted in Fig. 12b. The error values are generally larger than those caused by the effective radius uncertainty with the root-mean square of $15 \%$. Obviously, the larger errors are for optically thicker clouds.

To better understand the total error resulting from the uncertainties in both effective radius $R_{\text {eff }}$ and calibration coefficient $C$, we assume that both uncertainties are normally distributed (see insets in Figs. 13a and 13b with a mean of $10 \mu \mathrm{m}$ and a standard deviation of $3 \mu \mathrm{m}$ for $R_{\text {eff }}$ and a mean of $6.38 \mathrm{~W} \mathrm{~m}^{-2} \mathrm{sr}^{-1} \mu \mathrm{m}^{-1} /$ (photon counts/bin) and a standard deviation of $2.5 \%$ for $C$. (Note that, while simulating the sensitivity to effective radius, we used a truncated normal distribution rejecting $R_{\text {eff }}$ below 6 and above $16 \mu \mathrm{m}$.) The distribution of the retrieved COD values is calculated using a straightforward Monte Carlo procedure picking randomly realizations of $R_{\text {eff }}$ and $C$. Figure 13 shows two examples for thicker (Fig. 13a) and thinner clouds (Fig. 13b). For the thicker cloud, the solar background was 32.1 (photon counts/bin); for the thinner cloud it was 18.7 (photon counts/bin). The calibration coefficient $C=6.38 \mathrm{~W}$ $\mathrm{m}^{-2} \mathrm{sr}^{-1} \mu \mathrm{m}^{-1} /($ photon counts/bin) and effective radius $R_{\text {eff }}=10 \mu \mathrm{m}$ lead to a COD $=37$ and 11 for the thicker and thinner clouds, respectively. With normally distributed uncertainties in $R_{\text {eff }}$ and $C$, the resulting

$\leftarrow$

smaller than $25 \%$ of their mean values. Regression equations and the correlation coefficients are shown. (c) Radiance distributions of the GLAS data used in the calculations for the two selected points marked in (a). 

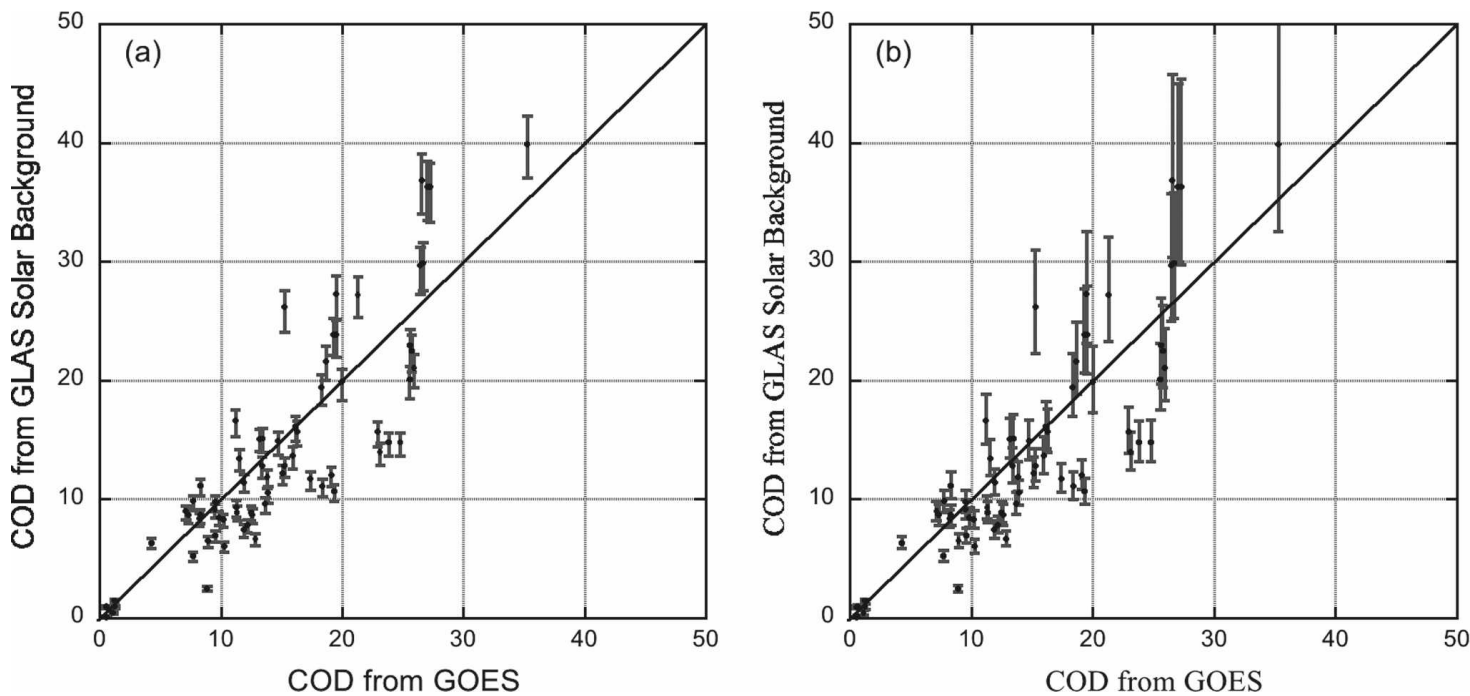

FIG. 12. As in Fig. 11b but the possible errors of retrievals from the GLAS 532-nm channel are also shown: errors resulting from (a) the uncertainty in droplet effective radius (from 6 to $16 \mu \mathrm{m}$ ) and (b) the uncertainty in calibration coefficient $(5 \%)$.

COD distribution has a mean of 37 and a standard deviation of 4 for the thicker cloud, and a mean of 11 and a standard deviation of 0.6 for the thinner one. This translates to $11 \%$ and $6 \%$ one-standard-deviation errors for the thicker and thinner clouds, respectively.

\section{A marine stratocumulus case study}

To further illustrate how GLAS passive remote sensing complements GLAS active remote sensing, we show an example that involves a thick marine stratocumulus cloud. The marine stratocumulus scene (Fig. 14a) was observed by GLAS on 1 November 2003. The scene, which extended over $900 \mathrm{~km}$, was taken over the southern Pacific Ocean from $35.13^{\circ}-43.29^{\circ} \mathrm{S}, 84.30^{\circ}-$ $85.80^{\circ} \mathrm{W}$. The cloud deck is optically thick and the standard GLAS active remote sensing was unable to retrieve its optical depth. However, this information can be obtained using solar background signal. Figure 14b shows the retrieved COD field. The average COD for this scene is 11 , which is typical for marine stratocumulus clouds.

With the empirical Eq. (9) from Minnis et al. (1992) derived for marine stratocumulus, its geometrical thickness $\Delta h(\mathrm{~m})$ can be estimated based on COD $\tau$ as

$$
\Delta h=0.452 \tau^{2 / 3} .
$$

Applying this statistical expression everywhere, as if it were deterministic, we find the average geometrical thickness of the clouds in the scene to be $\sim 260 \mathrm{~m}$. This value is as reasonable as can be expected since the cloud type here is the same as for the Minnis et al. study. Cloud top height is determined by GLAS active remote sensing and is a standard GLAS product (GLA09). In addition to cloud top height, Fig. 14c also shows the cloud base height determined by subtracting cloud thickness $\Delta h$ from cloud top height. As a result, if the empirical relationship between $\Delta h$ and $\tau$ is used on a per-shot basis, passive remote sensing complements the active remote sensing by determining cloud base heights when the clouds are too thick to be penetrated by laser beams, at least for such marine stratocumulus cloud layers.

Although related statistically for some cloud types, $\Delta h$ and $\tau$ are in reality independent cloud properties even in marine stratocumulus. We note for completeness the recent development of lidar techniques that exploit the component of laser-pulse returns made entirely of multiply scattered light, which is normally viewed (like sunlight) as a nuisance in lidar data processing. Simultaneous retrievals of $\Delta h$ and $\tau$ from multiple scattering returns have been demonstrated for ground-based (Polonsky et al. 2005), airborne (Cahalan et al. 2005), and even space-based (Davis et al. 2001) lidar systems. Fundamentally, this new active approach to optical cloud remote sensing uses the natural timedependent extension of our present signal from the steady solar source.

\section{Conclusions}

It has been suggested by Platt et al. $(1998,2006)$ that solar background count rates in spaceborne lidar re- 


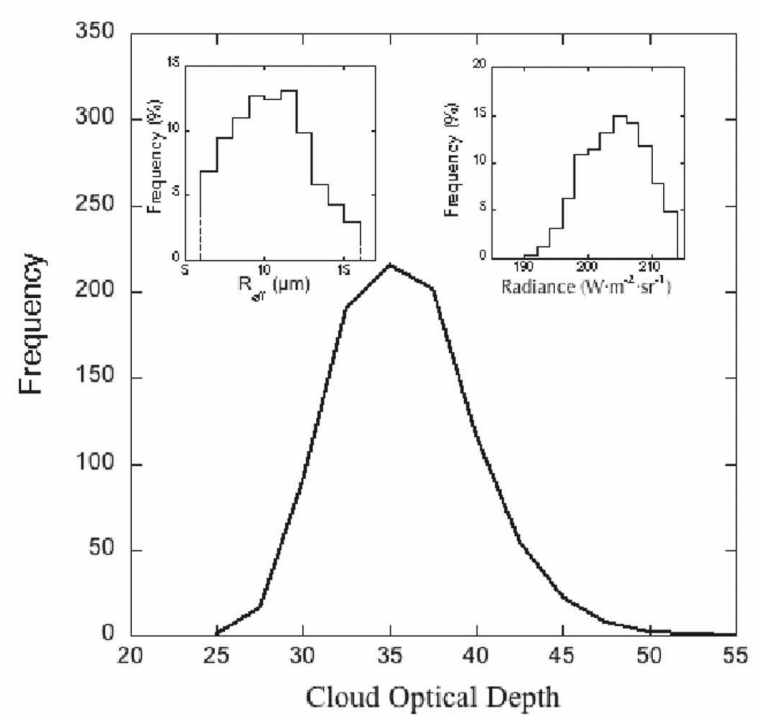

(a)

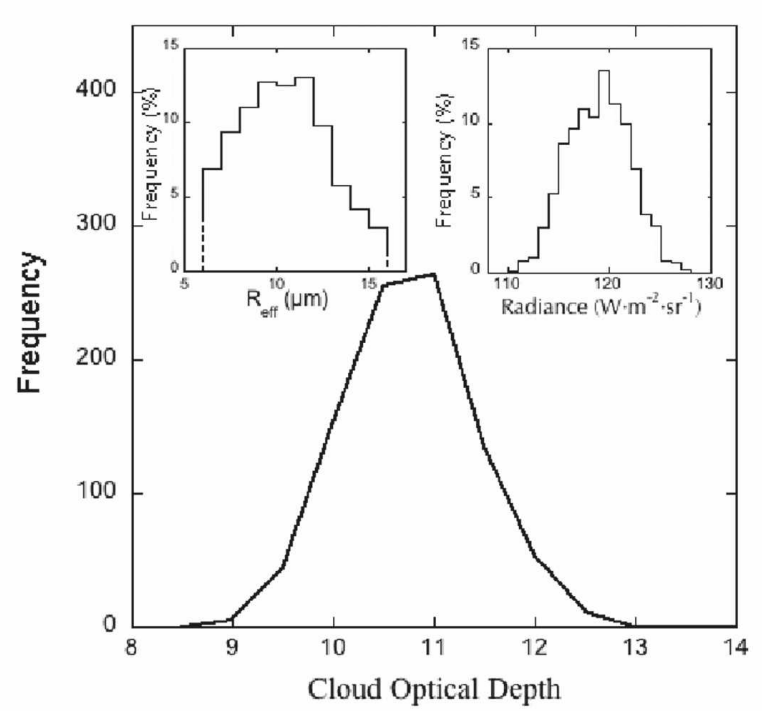

(b)

FIG. 13. Examples of the error analysis in the retrieved cloud optical depth (COD) for thicker (a) and thinner clouds (b). Insets show the assumed uncertainties in effective radius, $R_{\text {eff }}$, and the calibrated background radiance resulted from the uncertainties in the calibration coefficient, $C: R_{\text {eff }}$ and $C$ are assumed to be normally distributed [note that the small $\left(R_{\text {eff }}<6 \mu \mathrm{m}\right)$ and large $\left(R_{\text {eff }}>16 \mu \mathrm{m}\right)$ values have been rejected]. Mean $R_{\text {eff }}=10 \mu \mathrm{m}$ with standard deviation (std) $3 \mu \mathrm{m}$, and mean $C=6.38 \mathrm{~W}$ $\mathrm{m}^{-2} \mathrm{sr}^{-1} \mu \mathrm{m}^{-1} /($ photon counts/bin) with std of $2.5 \%$ lead to mean $\mathrm{COD}=37$ with std 4 and to $\mathrm{COD}=11$ with std 0.6 , for the thicker and thinner clouds, respectively.

turns can be used to infer cloud optical depth as long as they are properly calibrated. In this paper, we examined three possible ways of calibrating the reflected solar radiation that reaches GLAS 532-nm channel pho- ton-counting detectors. In so doing, we turn solar background radiation, which so far has been regarded as noise to be subtracted in the retrieval process of the lidar products, into a signal that could be used in retrieving the optical depth of optically thick clouds, which cannot be penetrated by the GLAS lasers. The three independent calibration methods investigated are (i) calibration with collocated airborne and GLAS observations, (ii) calibration with collocated deepconvection clouds from GOES and GLAS observations, and (iii) calibration from first principles using optical depth of thin water clouds over ocean retrieved by GLAS active remote sensing. The main results are the following:

(i) The calibration results from the three methods agree well with each other and the differences among the calibration coefficients are within $4.2 \%$. Consolidating all data used in the calibration, we determined the final calibration coefficient to be $6.38 \mathrm{~W} \mathrm{~m}^{-2} \mathrm{sr}^{-1} \mu \mathrm{m}^{-1}$ (photon counts/bin).

(ii) Cloud optical depths retrieved from calibrated GLAS 532-nm solar background radiances match those from the GOES satellites fairly well when the inhomogeneity of the cloud field is accounted for. The retrievals from the two instruments have a correlation coefficient 0.87 with essentially no bias. On average, the difference between COD retrieved from GOES and GLAS overpasses is $24 \%$, a value similar to the difference between optical depths derived from satellite and surface instrumentation. The GLAS rms retrieval errors resulting from effective radius uncertainty are about $7 \%$, whereas the errors from possible calibration uncertainty are on the order of $15 \%$.

(iii) The retrievals have been demonstrated for a GLAS scene with marine stratocumulus clouds too thick for the GLAS laser to penetrate. In addition to cloud top height retrieved from GLAS active remote sensing, we used the GLAS calibrated solar background signal to retrieve cloud optical depth. As an example, we then converted cloud optical depth into cloud geometrical thickness using an empirical relationship derived for marine stratocumulus (Minnis et al. 1992). This, combined with the direct lidar measurement of cloud top, allowed us to estimate cloud base.

Based on this study, optical depths for thick clouds will be provided as a supplementary product to the existing operational GLAS cloud products in future GLAS data releases. Even though in this study we used a marine stratocumulus example to illustrate how extra information can be obtained from the solar background 

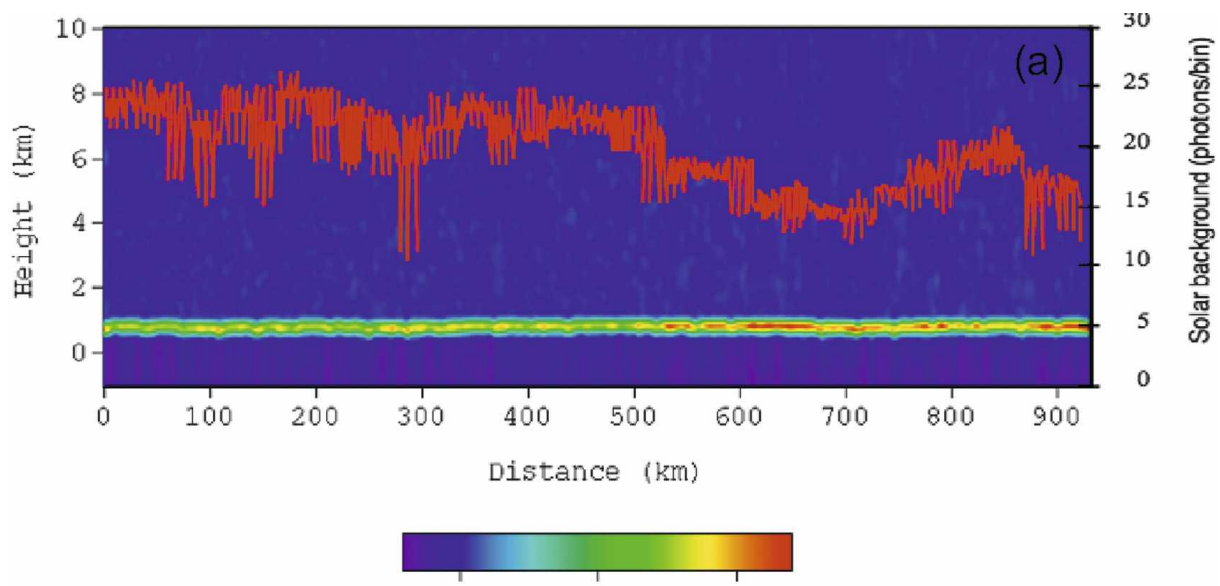

$0.00000 \quad 0.00004 \quad 0.00007$

Attenuated backscatter (1/m*sr)
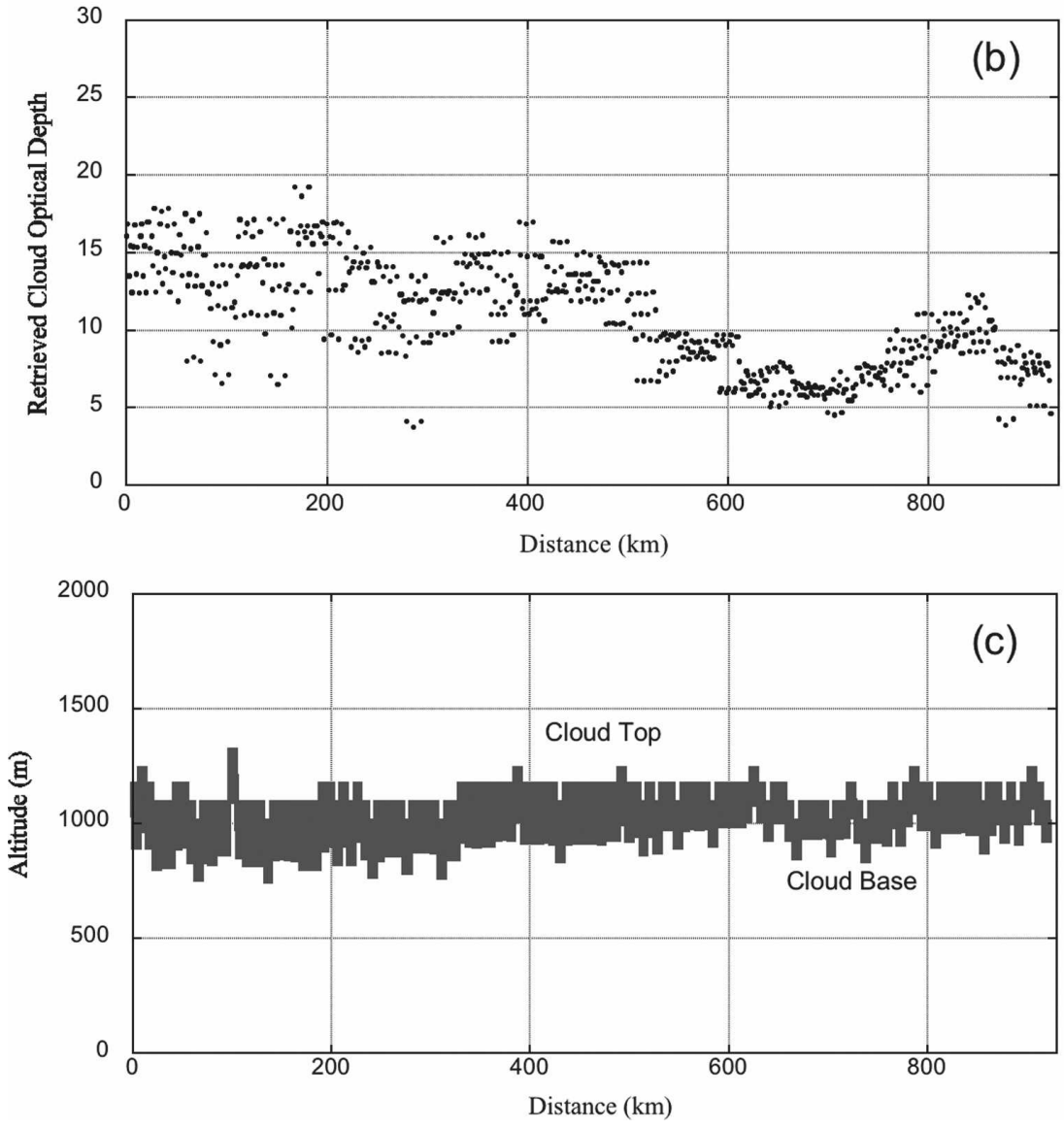

FIG. 14. A marine stratocumulus scene over the southern Pacific Ocean observed on 1 November 2003: (a) GLAS $532 \mathrm{~nm}$ backscattering image and the corresponding solar background photon counts in the unit of Photons/bin; (b) COD retrieved from GLAS $532 \mathrm{~nm}$ solar background at resolution $0.2 \mathrm{~s}(1.4 \mathrm{~km})$ ); and (c) cloud top observed by GLAS mapped to the same resolution as in panel (b) and cloud base derived from an empirical equation (Minnis et al. 1992). 
signal, the ultimate goal is to provide cloud optical depth for all types of clouds detected by GLAS. For optically thin clouds, it has already been done with GLAS active remote sensing; for all optically thick clouds (stratiform or not) the new method proposed above will be applied. The retrievals will be conducted over all surface types. Of course, uncertainty on the retrieved COD will increase in the presence of broken cloud fields and/or when shadows are cast from higher clouds due to 3D radiative effects (Davies 2005), but this is no different than for other operational cloud products.

The methods presented in this paper, even though implemented for GLAS, can be used to calibrate solar background signals for other spaceborne lidar instruments, such as the Lidar In-Space Technology Experiment (LITE) on the space shuttle Discovery and the Cloud-Aerosol Lidar with Orthogonal Polarization (CALIOP) onboard CALIPSO. We understand that CALIPSO, as a part of A-train, has MODIS onboard Aqua flying only $15 \mathrm{~s}$ apart. Furthermore, CALIPSO itself has a wide field camera (FWC) that takes measurements at $645 \mathrm{~nm}$ and is designed to match the Aqua MODIS instrument channel 1. However, for current and future missions without the advantages that CALIPSO has (e.g., ICESat II), the methods studied in this paper provide examples to follow.

Acknowledgments. The authors thank Drs. Tamás Várnai, William Hart, David Doelling, and Kristine Barbieri for helpful discussions and advice. This work was supported by NASA's ICESat Science Project.

\section{REFERENCES}

American Society for Testing and Materials, 2000: Standard E-490-00: Standard solar constant and air mass zero solar spectral irradiance tables. Annual Book of ASTM Standards 2000, ASTM International, 473-488.

Cahalan, R. F., M. J. McGill, J. Kolasinski, T. Várnai, and K. Yetzer, 2005: THOR-Cloud thickness from offbeam lidar returns. J. Atmos. Oceanic Technol., 22, 605-627.

Campbell, J. R., D. L. Hlavka, E. J. Welton, C. J. Flynn, D. D. Turner, J. D. Spinhirne, V. S. Scott, and I. H. Hwang, 2002: Full-time, eye-safe cloud and aerosol lidar observation at atmospheric radiation measurement program sites: Instruments and data processing. J. Atmos. Oceanic Technol., 19, 431-442.

Chiu, J. C., A. Marshak, W. J. Wiscombe, S. C. Valencia, and E. J. Welton, 2007: Cloud optical depth retrievals from solar background "signals" of micropulse lidars. IEEE Geosci. Remote Sens. Lett., 4, 456-460.

Cox, C., and W. Munk, 1954: Measurement of the roughness of the sea surface from photographs of the sun's glitter. J. Opt. Soc. Amer., 44, 838-850.

Davies, R., 2005: 3D radiative transfer in satellite remote sensing of cloud properties. 3D Radiative Transfer in Cloudy Atmo- spheres, A. Marshak and A. B. Davis, Eds., Springer-Verlag, $153-242$.

Davis, A. B., D. M. Winker, and M. A. Vaughan, 2001: First retrievals of dense cloud properties from off-beam/multiplescattering lidar data collected in space. Proc. 20th Int. Laser Radar Conf., Vichy, France, École Polytechnique, 35-38.

Dong, X., G. G. Mace, P. Minnis, W. L. Smith Jr., M. Poellot, R. T. Marchand, and A. D. Rapp, 2002: Comparison of stratus cloud properties deduced from surface, GOES, and aircraft data during the March 2000 ARM cloud IOP. J. Atmos. Sci., 59, 3265-3284.

, P. Minnis, B. Xi, S. Sun-Mack, and Y. Chen, 2008: Comparison of CERES-MODIS stratus cloud properties with ground-based measurements at the DOE ARM Southern Great Plains site. J. Geophys. Res., 113, D03204, doi:10.1029/ 2007JD008438.

Hart, W. D., J. D. Spinhirne, S. P. Palm, and D. L. Hlavka, 2005: Height distribution between cloud and aerosol layers from the GLAS spaceborne lidar in the Indian Ocean region. Geophys. Res. Lett., 32, L22S06, doi:10.1029/2006GLO23671.

Hlavka, D. L., S. P. Palm, W. D. Hart, J. D. Spinhirne, M. J. McGill, and E. J. Welton, 2005: Aerosol and cloud optical depth from GLAS: Results and verification for an October 2003 California fire smoke case. Geophys. Res. Lett., 32, L22S07, doi:10.1029/2005GL023413.

Hook, S. J., J. J. Myers, K. J. Thome, M. Fitzgerald, and A. B. Kahle, 2001: The MODIS/ASTER airborne simulator (MASTER)-A new instrument for earth science studies. Remote Sens. Environ., 76, 93-102.

Loeb, N. G., K. J. Priestley, D. P. Kratz, E. B. Geier, R. N. Green, B. A. Wielicki, P. O. Hinton, and S. K. Nolan, 2001: Determination of unfiltered radiances from the Clouds and the Earth's Radiant Energy System instrument. J. Appl. Meteor., 40, 822-835.

Minnis, P., P. W. Heck, D. F. Young, C. W. Fairall, and J. B. Snider, 1992: Stratocumulus cloud properties derived from simultaneous satellite and island-based instrumentation during FIRE. J. Appl. Meteor., 31, 317-339.

_- and Coauthors, 1995: Cloud optical property retrieval: Clouds and the Earth's Radiant Energy System (CERES) algorithm theoretical basis document. Vol. III, Cloud analyses and radiance inversions (Subsystem 4), NASA Rep. 1376, 135-176.

— D. P. Garber, D. F. Young, R. F. Arduini, and Y. Takano, 1998: Parameterization of reflectance and effective emittance for satellite remote sensing of cloud properties. J. Atmos. Sci., 55, 3313-3339.

—, L. Nguyen, D. R. Doelling, D. F. Young, W. F. Miller, and D. P. Kratz, 2002: Rapid calibration of operational and research meteorological satellite imagers. Part I: Evaluation of research satellite visible channels as references. J. Atmos. Oceanic Technol., 19, 1233-1249.

Nguyen, L., P. Minnis, J. K. Ayers, and D. R. Doelling, 2001: Intercalibration of meteorological satellite imagers using VIRS, ATSR-2, and MODIS. Proc. 11th Conf. on Satellite Meteorology and Oceanography, Madison, WI, Amer. Meteor. Soc., 442-445.

Palm, S. P., W. D. Hart, D. L. Hlavka, E. Welton, A. Marsh, and J. D. Spinhirne cited 2002: GLAS atmospheric data products. Geoscience Laser Altimeter System (GLAS) algorithm theoretical basis document, version 4.2. Goddard Space Flight Center, 137 pp. [Available online at http://www.csr.utexas. edu/glas/pdf/glasatmos.atbdv4.2.pdf.] 
Platt, C. M. R., W. H. Hunt, D. M. Winker, and M. A. Vaughan, 1998: Measurement of cloud solar reflected radiance and extinction from space lidar. Optical Remote Sensing for Industry and Environmental Monitoring, U. N. Singh, H. Hu, and G. Wang, Eds., International Society for Optical Engineering, (SPIE Proceedings, Vol. 3504), 542-549.

, S. D. Miller, and W. H. Hunt, 2006: Solar radiance and albedo of clouds from space lidar. Proc. 23rd Int. Laser Radar Conf., Nara, Japan, International Coordination Group for Laser Atmospheric Studies, 1023-1026.

Polonsky, I. N., S. P. Love, and A. B. Davis, 2005: Wide-angle imaging lidar deployment at the ARM southern Great Plains site: Intercomparison of cloud property retrievals. J. Atmos. Oceanic Technol., 22, 628-648.

Spinhirne, J. D., S. P. Palm, and W. D. Hart, 2005a: Antarctica cloud cover for October 2003 from GLAS satellite lidar profiling. Geophys. Res. Lett., 32, L22S05, doi:10.1029/ 2005 GL023782.

,,,--- D. L. Hlavka, and E. J. Welton, 2005b: Cloud and aerosol measurements from GLAS: Overview and initial results. Geophys. Res. Lett., 32, L22S03, doi:10.1029/ 2005 GL023507.

Stamnes, K., S.-C. Tsay, W. J. Wiscombe, and K. Jayaweera, 1988: Numerically stable algorithm for discrete-ordinate-method radiative transfer in multiple scattering and emitting layered media. Appl. Opt., 27, 2502-2509.

Valencia, S. C., C. K. Currie, E. J. Welton, and T. A. Berkoff, 2004: Development of a radiance data product using the micropulse lidar. Proc. 22nd Int. Laser Radar Conf., Matera, Italy, European Space Agency, 287-290. 